\title{
Neoadjuvant versus adjuvant treatment: which one is better for resectable esophageal squamous cell carcinoma?
}

Yaping $\mathrm{Xu}^{1+}$, Xinmin $\mathrm{Yu}^{2 \dagger}$, Qixun $\mathrm{Chen}^{3+}$ and Weimin $\mathrm{Mao}^{3^{*+}}$

\begin{abstract}
Esophageal cancer is the eighth most common cancer worldwide, and especially in some areas of China is the fourth most common cause of death and is of squamous cell carcinoma (SCC) histology in $>90 \%$ of cases. Surgery alone was the mainstay of therapeutic intervention in the past, but high rates of local and systemic failure have prompted investigation into multidisciplinary management. In this review, we discuss the key issues raised by the recent availability of esophageal SCC treatment with the addition of chemotherapy, radiotherapy, and chemoradiotherapy to the surgical management of resectable disease and discuss how clinical trials and meta-analysis inform current clinical practice. None of the randomized trials that compared neoadjuvant radiotherapy or chemotherapy with surgery alone in esophageal SCC has demonstrated an increase in overall survival in those patients treated with neoadjuvant radiotherapy or chemotherapy. Neoadjuvant chemoradiotherapy has been accepted recently for esophageal cancer because such a regimen offers great opportunity for margin negative resection, improved loco-regional control and increased survival. The majority of the available evidence currently reveals that only selected locally advanced esophageal SCC are more likely to benefit from the adjuvant therapy. The focus of future trials should be on identification of the optimum regimen and should aim to minimize treatment toxicities and effect on quality of life, as well as attempt to identify and select those patients most likely to benefit from specific treatment options.
\end{abstract}

Keywords: Esophageal cancer, Squamous cell carcinoma, Neoadjuvant therapy, Adjuvant therapy, Chemotherapy, Radiotherapy, Chemoradiotherapy

\section{Review}

\section{Introduction}

Esophageal cancer is the most rapidly increasing tumor type in the world $[1,2]$. Globally, esophageal cancer is the eighth most common malignancy and sixth most fatal disease, with approximately 460,000 new diagnoses and $>380,000$ deaths annually [3]. More than one-half of new cases in western countries have adenocarcinoma (AC) of the lower esophagus or gastroesophageal junction; and $>90 \%$ patients in eastern Asian countries have squamous cell carcinoma (SCC) [3,4].

\footnotetext{
*Correspondence: maowmzj1218@163.com

${ }^{\dagger}$ Equal contributors

${ }^{3}$ Department of Thoracic Surgery, Zhejiang Cancer Hospital, Hangzhou 310022, Zhejiang, People's Republic of China

Full list of author information is available at the end of the article
}

Despite improvements in surgical and radiotherapy (RT) techniques and refinements of chemotherapeutic regimens, long-term survival, even from localized esophageal cancer, remains poor. Surgery alone was the mainstay of therapeutic intervention in the past, but high rates of local and systemic failure have prompted investigation into the multidisciplinary management. Treatment paradigms differ between western and Asian countries, but the unifying theme that has emerged in the past decade implies that surgery alone can no longer be considered the standard of care. In attempts to improve the survival rate, the multidisciplinary management involved various combinations and sequences of all modalities including surgery, RT, chemotherapy (CT), and chemoradiotherapy (CRT).

The prognosis was different slightly between histological subtypes. Prior studies have shown that, in

\section{Biomed Central}


comparison with patients with $\mathrm{AC}$, those with esophageal SCC have worse prognosis [5-7]. This difference is probably due to a different pattern of lymphatic spread and a greater tendency for the disease to spread locally $[8,9]$, but more importantly due to the location of the primary tumor. SCC is usually a proximal lesion, with $75 \%$ of these cancers found to have contact with the tracheobronchial tree, while $94 \%$ of AC are below the tracheal bifurcation [10].

Neoadjuvant CRT is currently the standard of care for esophageal AC in many western countries. However, the optimal treatment strategy for resectable esophageal SSC is still a controversial topic. In this review, we discuss the key issues raised by the recent availability for esophageal SCC treatment with the addition of RT, CT, and CRT to the surgical management of resectable disease, and discuss how clinical trials and meta-analysis inform current clinical practice.

\section{Neoadjuvant treatments}

\section{Neoadjuvant radiotherapy}

There have been five phase III randomized trials comparing neoadjuvant RT with surgery alone [11-15] in esophageal SCC (Table 1) and none has demonstrated an increase in resectability or overall survival (OS) in those treated with neoadjuvant RT. Although Nygaard and colleagues reported a 3-year OS benefit, this was only after pooling patients who had received neoadjuvant RT with those who had also received neoadjuvant CRT, as there was no significant difference in survival found otherwise [14]. Meta-analysis of the five above mentioned randomized trials only proved a nonstatistically significant trend (hazard ratio (HR): 0.91, 95\% CI: 0.80 to 1.04 ) in favor of neoadjuvant RT [16].

A recent meta-analysis of trials including data from 1,033 patients, $33 \%$ of whom presented SCC, revealed significantly improved median OS (27 months vs. 18 months, $P<0.0001)$ and cause-specific survival (35 months vs. 21 months, $P<0.0001$ ) with neoadjuvant RT. These results support the use of neoadjuvant RT for patients with esophageal cancer, but patients with SCC were not analyzed separately [17]. Given the lack of demonstrated significant benefits of neoadjuvant RT in SCC patients, a preoperative neoadjuvant radiation treatment strategy is currently not recommended in the SCC population.

\section{Neoadjuvant chemotherapy}

The theoretical advantages of adding CT to the treatment of esophageal cancer are potential tumor downstaging prior to surgery, as well as targeting micrometastatic disease and thus decreasing the risk of distant spread. Potential drawbacks include morbidity and mortality associated with CT toxicity, selection of drug-resistant clones, and delay in definitive surgical management.

Early randomized trials using cisplatin, fluorouracil (5-FU), bleomycin, vindesine and their combinations were conducted in patients with SCC of the esophagus [14,18-21] (Table 2). However, these trials were underpowered to detect any difference in outcome with the addition of CT to surgery. Three-year OS rates ranged from 3 to $43 \%$, despite the use of very similar CT regimens. Two large randomized studies that evaluated neoadjuvant $\mathrm{CT}$ with cisplatin and 5-FU for operable esophageal AC or SCC had contrasting results. The smaller Radiation Therapy Oncology Group trial 8911 (US Inter group 113) study reported no survival benefit, with a median survival of 14.9 months in patients treated with CT compared with 16.1 months in those receiving surgery alone $(P=0.53)$ [22]. Only $31 \%$ of patients in the larger multi-institutional Medical Research Council OE02 study had SCC, reflecting the increasing relative incidence of esophageal AC in the UK.

Table 1 Randomized controlled trials of neoadjuvant radiotherapy versus surgery alone for esophageal squamous cell carcinoma

\begin{tabular}{|c|c|c|c|c|c|c|c|}
\hline Study & Histology & SCC (\%) & Treatment & $n$ & MS (months) & 5-year OS (\%) & $P$ value \\
\hline \multirow[t]{2}{*}{ Launois and colleagues [11] } & SCC & 100 & NART 40 Gy & 77 & 10 & 10 & NS \\
\hline & & & Surgery & 57 & 12 & 12 & \\
\hline \multirow[t]{2}{*}{ Gignoux and colleagues [12] } & SCC & 100 & NART 33 Gy & 106 & 11 & 11 & NS \\
\hline & & & Surgery & 102 & 11 & 10 & \\
\hline \multirow[t]{2}{*}{ Arnott and colleagues [13] } & AC/SCC & 36 & NART 20 Gy & 90 & 8 & 9 & NS \\
\hline & & & Surgery & 86 & 8 & 17 & \\
\hline \multirow[t]{2}{*}{ Nygaard and colleagues [14] } & SCC & 100 & NART 35 Gy & 48 & & $21^{\mathrm{a}}$ & NS \\
\hline & & & Surgery & 41 & & $9^{a}$ & \\
\hline \multirow[t]{2}{*}{ Wang and colleagues [15] } & SCC & 100 & NART 40 Gy & 104 & & 35 & NS \\
\hline & & & Surgery & 102 & & 30 & \\
\hline
\end{tabular}

${ }^{a}$ Three-year overall survival (OS). AC adenocarcinoma, MS median survival, NART neoadjuvant radiotherapy, NS not significant, SCC squamous cell carcinoma. 


\begin{tabular}{|c|c|c|c|c|c|c|c|}
\hline Study & Histology & SCC (\%) & Treatment & $n$ & MS (months) & 3-year OS (\%) & $P$ value \\
\hline \multirow[t]{2}{*}{ Schlag [18] } & SCC & 100 & CF & 22 & 7 & & NS \\
\hline & & & Surgery & 24 & 6 & & \\
\hline \multirow[t]{2}{*}{ Nygaard and colleagues [14] } & SCC & 100 & $\mathrm{BC}$ & 44 & 7 & 3 & NS \\
\hline & & & Surgery & 41 & 7 & 9 & \\
\hline \multirow[t]{2}{*}{ Maipang and colleagues [19] } & SCC & 100 & BVC & 24 & 17 & 31 & NS \\
\hline & & & Surgery & 22 & 17 & 36 & \\
\hline \multirow[t]{2}{*}{ Law and colleagues [20] } & SCC & 100 & CF & 74 & 17 & 40 & NS \\
\hline & & & Surgery & 73 & 13 & 13 & \\
\hline \multirow[t]{2}{*}{ Ancona and colleagues [21] } & SCC & 100 & $\mathrm{CF}$ & 47 & 25 & $34^{\mathrm{a}}$ & NS \\
\hline & & & Surgery & 47 & 24 & $22^{\mathrm{a}}$ & \\
\hline \multirow[t]{2}{*}{ Kelsen and colleagues [22] } & $\mathrm{AC} / \mathrm{SCC}$ & 54 & $\mathrm{CF}$ & 213 & 15 & $19^{\mathrm{a}}$ & NS \\
\hline & & & Surgery & 227 & 16 & $20^{\mathrm{a}}$ & \\
\hline \multirow[t]{2}{*}{ Allum and colleagues [23] } & $\mathrm{AC} / \mathrm{SCC}$ & 31 & CF & 400 & 17 & 43 & $<0.01$ \\
\hline & & & Surgery & 402 & 13 & 34 & \\
\hline
\end{tabular}

${ }^{a}$ Five-year overall survival (OS). AC adenocarcinoma, BC bleomycin + cisplatin, BVC bleomycin + vindesine + cisplatin, CF cisplatin + fluorouracil, MS median survival, NS not significant, SCC squamous cell carcinoma.

Five-year OS was increased by $6 \%$ from 17.1 to $23 \%$ (HR: $0.84,95 \% \mathrm{CI}: 0.72$ to $0.98 ; P=0.03$ ) with the addition of CT to surgery [23]. The discrepancy between the results of the Radiation Therapy Oncology Group trial 8911 [22] and OE02 [23] studies is due to the larger proportion of patients with SCC in the former trial who do not appear to significantly benefit from this strategy.

In 2008 a Japan Clinical Oncology Group study (JCOG 9907) comparing adjuvant and neoadjuvant CT was reported, and those results showed that neoadjuvant CT induced down-staging and R0 reduction and improved OS without additional serious adverse events [24]. However, the efficacy of neoadjuvant CT was not compared with surgery alone in this randomized trial. Prior to the JCOG 9907 study, the authors had compared adjuvant CT and surgery alone in the JCOG 9204 study. They found that the addition of adjuvant CT improved the disease-free survival rate (from 45 to $55 \% ; P=0.037$ ) and the pN1 subgroup 5 -year OS ( $52 \%$ vs. $38 \%, P=0.041)$; however, there was no significant difference in the 5 -year OS of the entire cohort (61\% with CT vs. $52 \%$ with observation; $P=0.13$ ) [25]. From these data, JCOG 9907 implied that neoadjuvant CT was more beneficial than surgery alone. Up to now, however, none of the randomized trials that compared neoadjuvant $\mathrm{CT}$ with surgery alone in esophageal SCC has demonstrated an increase in OS in those patients treated with neoadjuvant CT.

In an updated meta-analysis by Sjoquist and colleagues of nine randomized trials comparing neoadjuvant CT with surgery alone, in all histological subtypes an HR of
0.87 was reported (95\% CI: 0.79 to $0.96 ; P=0.05$ ) [26]. There was no significant benefit for patients with SCC (HR: 0.92 , 95\% CI: 0.81 to $1.04 ; P=0.18$ ).

\section{Neoadjuvant chemoradiotherapy}

CT combined with RT was initially evaluated as a definitive treatment for patients identified as unable to proceed with surgery [27]. In combination, CT not only complements but increases the effect of RT in a process known as radiation sensitization, as well as complementing synergistic DNA damage, cell cycle synchronization, and inhibition of repair pathways [28]. In addition to increasing the efficacy of RT and thus controlling local tumor growth, CT theoretically also offers the ability to eradicate micrometastatic disease and decrease the risk of distant recurrence [29].

Several trials have investigated neoadjuvant concurrent CRT in esophageal SCC compared with surgery alone [30-36] (Table 3). The results of a phase III randomized controlled study (FFCD 9901) showed that neoadjuvant CRT with cisplatin and 5-FU did not improve OS but enhanced the postoperative mortality rate for patients with localized stage I or stage II esophageal cancer compared with surgery alone [31]. Another two studies reported no survival benefit with the addition of CRT with cisplatin and 5-FU regimens [32,33]. A larger study that randomized 256 patients with either AC or SCC to receive concurrent $\mathrm{CRT}$ or surgery alone reported no difference in OS between the two arms. However, a subgroup analysis demonstrated a significant improvement in progression-free survival (HR: $0.47,95 \% \mathrm{CI}: 0.25$ to 0.86), although not in OS for the smaller subgroup of 


\begin{tabular}{|c|c|c|c|c|c|c|c|}
\hline Study & Histology & SCC (\%) & Treatment & $n$ & MS (months) & 5-year OS (\%) & $P$ value \\
\hline \multirow[t]{2}{*}{ Bosset and colleagues [30] } & SCC & 100 & $C+37$ Gy & 143 & 19 & 7 & NS \\
\hline & & & Surgery & 139 & 19 & 9 & \\
\hline \multirow[t]{2}{*}{ Lee and colleagues [32] } & SCC & 100 & $C F+45 G y$ & 51 & 28 & $49^{\mathrm{a}}$ & NS \\
\hline & & & Surgery & 50 & 27 & $41^{\mathrm{a}}$ & \\
\hline \multirow[t]{2}{*}{ Burmeister and colleagues [34] } & $\mathrm{AC} / \mathrm{SCC}$ & 35 & $C F+35$ Gy & 128 & 22 & 17 & NS \\
\hline & & & Surgery & 128 & 19 & 13 & \\
\hline \multirow[t]{2}{*}{ Natsugoe and colleagues [33] } & SCC & 100 & $C F+40 \mathrm{~Gy}$ & 22 & & 57 & 0.58 \\
\hline & & & Surgery & 23 & & 41 & \\
\hline \multirow[t]{2}{*}{ Tepper and colleagues [35] } & $\mathrm{AC} / \mathrm{SCC}$ & 25 & $C F+50.4 \mathrm{~Gy}$ & 30 & 54 & 39 & $<0.01$ \\
\hline & & & Surgery & 26 & 21 & 16 & \\
\hline \multirow[t]{2}{*}{ Mariette and colleagues [31] } & $\mathrm{AC} / \mathrm{SCC}$ & 66 & $C F+45 \mathrm{~Gy}$ & 97 & 32 & $49^{\mathrm{a}}$ & 0.68 \\
\hline & & & Surgery & 98 & 44 & $55^{\mathrm{a}}$ & \\
\hline \multirow[t]{2}{*}{ Gaast and colleagues [36] } & $\mathrm{AC} / \mathrm{SCC}$ & 24 & $P C+41.4 \mathrm{~Gy}$ & 175 & 49 & $59^{\mathrm{a}}$ & 0.011 \\
\hline & & & Surgery & 188 & 26 & $48^{\mathrm{a}}$ & \\
\hline
\end{tabular}

${ }^{a}$ Three-year overall survival (OS). AC adenocarcinoma, C cisplatin, CF cisplatin + fluorouracil, MS median survival, NS not significant, PC paclitaxel + carboplatin, SCC squamous cell carcinoma.

patients with SCC [34]. The Cancer and Leukemia Group B 9781 trial of neoadjuvant cisplatin and 5-FU in weeks 1 and 5 with RT (50.4 Gy in 28 fractions) compared with surgery alone closed to accrual prematurely having recruited only 56 of the planned 475 patients with resectable SCC or AC, owing to slow recruitment. Despite the limited sample size, 5-year OS was significantly improved from 16 to $39 \%$ in the trimodality arm and the pathological complete response rate was $40 \%$ [35]. Results from a recent multicenter phase III randomized trial (CROSS study) showed that neoadjuvant CRT with carboplatin and paclitaxel improved OS compared with surgery alone in patients with resectable (T2-3, N0-1, M0) esophageal or gastroesophageal junction cancers. The reported rate of $\mathrm{R} 0$ resection was higher in the CRT arm compared with the surgery alone arm (92\% vs. $65 \%)$. The OS was significantly better for patients treated with CRT. Median survival was 49 months in the CRT arm compared with 26 months in the surgery alone arm. The 1-year, 2-year and 3-year survival rates were $82 \%$, $67 \%$ and 59\% respectively in the CRT arm and 70\%, 52\% and $48 \%$ respectively in the surgery-alone arm [36].

The updated meta-analysis of 12 randomized compared neoadjuvant CRT with surgery alone. The HR for all-cause mortality for neoadjuvant CRT was 0.78 (95\% CI: 0.70 to $0.88 ; P<0.0001)$, the HR for SCC only was 0.80 (95\% CI: 0.68 to $0.93 ; P=0.004$ ) and the HR for AC only was 0.75 (95\% CI: 0.59 to $0.95 ; P=0.02$ ) [26]. Although this meta-analysis favors the neoadjuvant CRT approach for patients with SCC, this approach is also associated with significant treatment-related mortality and morbidity in this often malnourished population, who frequently have multiple smoking-related co-morbidities. The effectiveness of CRT with high pathological complete response rates prompted investigation of radical CRT as a definitive treatment modality to avoid surgical morbidity and mortality. The meta-analysis performed by Kranzfelder and colleagues, however, demonstrated that none of the randomized controlled trials was reporting an outcome of higher survival benefit after definitive CRT than neoadjuvant treatment followed by surgery, but treatment-related mortality rates were lower (HR 7.60; $P=0.007$ ) than with neoadjuvant treatment followed by surgery or surgery alone [37]. On the other hand, Akutsu and colleagues investigated the clinical and pathologic results of neoadjuvant CRT in 78 patients that underwent an esophagectomy after neoadjuvant CRT. They found that the clinical evaluation for CRT does not reflect the pathologic effectiveness; even if clinical complete response was achieved, viable cancer cells were still present at the primary site in the majority of the population [38].

\section{Adjuvant treatments}

Adjuvant radiotherapy

Adjuvant RT has also been evaluated in five small studies [39-43] (Table 4). A meta-analysis of these trials demonstrated no significant improvement in 5-year OS with the addition of RT to complete surgical resection [44].

Ténière and colleagues evaluated 221 patients with SCC of the middle to lower third of the esophagus who were randomized to adjuvant $\mathrm{RT}$ at a dose of 45 to 55 Gy versus observation [40]. They found that although local control improved from 15 to $30 \%$, there was no 
Table 4 Randomized controlled trials of adjuvant radiotherapy versus surgery alone for esophageal squamous cell carcinoma

\begin{tabular}{|c|c|c|c|c|c|c|c|}
\hline Studies & Histology & SCC (\%) & Treatment & $n$ & MS (months) & 5-year OS (\%) & $P$ value \\
\hline \multirow[t]{2}{*}{ Kunath and Fischer [39] } & SCC & 100 & ART 50 to 55 Gy & 23 & 9 & & NS \\
\hline & & & Surgery & 21 & 6 & & \\
\hline \multirow[t]{2}{*}{ Ténière and colleagues [40] } & SCC & 100 & ART 45 to 55 Gy & 102 & 18 & 19 & NS \\
\hline & & & Surgery & 119 & 18 & 19 & \\
\hline \multirow[t]{2}{*}{ Fok and colleagues [41] } & SCC & 100 & ART 43 to 53 Gy & 42 & 11 & 10 & NS \\
\hline & & & Surgery & 39 & 22 & 16 & \\
\hline \multirow[t]{2}{*}{ Zieren and colleagues [42] } & SCC & 100 & ART 56 Gy & 33 & & $23^{\mathrm{a}}$ & NS \\
\hline & & & Surgery & 35 & & $22^{\mathrm{a}}$ & \\
\hline \multirow[t]{2}{*}{ Xiao and colleagues [43] } & SCC & 100 & ART 50 to 60 Gy & 220 & & 41 & NS \\
\hline & & & Surgery & 275 & & 32 & \\
\hline
\end{tabular}

${ }^{a}$ Three-year overall survival (OS). ART adjuvant radiotherapy, MS median survival, NS, not significant, SCC squamous cell carcinoma.

survival benefit with the addition of adjuvant RT. Fok and colleagues also randomized 130 patients with esophageal carcinoma (SCC or AC) to observation versus adjuvant RT at a dose of 49.5 Gy in 3.5 Gy fractions [41]. They found that although local failure was reduced from 31 to $15 \%(P=0.06)$, the median OS was actually worse in the adjuvant RT arm (8.7 months vs. 15.2 months, $P=0.02$ ). This trial has been criticized, however, for the high dose per fraction that may have led to increased mortality in the radiation-containing arm. Zieren and colleagues randomized 68 patients with SCC to either adjuvant RT or surgery alone and found that adjuvant RT significantly increased the fibrotic stricture rate and did not improve OS or disease-free survival [42]. Malthaner and colleagues [44] performed a meta-analysis of 995 patients from five randomized trials of adjuvant RT versus observation. They found that there was no OS benefit with the addition of adjuvant RT, with a risk ratio for death at 1 year of 1.23 (95\% CI: 0.95 to $1.59, P=0.11$ ). Suggestions therefore indicate there are few data to suggest that adjuvant RT offers any survival benefit. However, both Ténière and colleagues [40] and Zieren and colleagues [42] included patients with positive celiac nodes (stage M1a). These patients represent a cohort at much higher risk for distant failure and therefore are less likely to benefit from adjuvant RT. Finally, the meta-analysis included the above flawed trials.

Xiao and colleagues [43] randomized 495 patients with esophageal SCC to radical resection alone versus adjuvant RT at a total dose of 50 to 60 Gy in 2 Gy fractions. Once again, there was no survival benefit for the entire cohort with the addition of adjuvant RT, with a 5-year OS of $31.7 \%$ for surgery alone versus $41.3 \%$ for adjuvant RT $(P=0.447)$. When stratifying based on stage, however, there was a significant survival benefit with adjuvant RT for stage III patients, with an improvement in 5-year OS from 13.1 to $35.1 \%,(P=0.003)$ but not for stage II patients. Similar to the findings mentioned above, Chen and colleagues retrospectively evaluated patients with thoracic esophageal SCC [45]. They reported that adjuvant $\mathrm{RT}$ was associated with a statistically significant improvement in survival, but only in those patients with three or more involved lymph nodes; no such association was found in patients with one or two involved lymph nodes.

In summary, the majority of the available evidence currently reveals that only selected locally advanced esophageal SCC are likely to benefit from adjuvant RT.

Table 5 Randomized controlled trials of adjuvant chemotherapy versus surgery alone for esophageal squamous cell carcinoma

\begin{tabular}{|c|c|c|c|c|c|c|c|}
\hline Study & Histology & SCC (\%) & Treatment & $n$ & MS (months) & 5-year OS (\%) & $P$ value \\
\hline \multirow[t]{2}{*}{ Pouliquen and colleagues [46] } & SCC & 100 & CF & 52 & 13 & & NS \\
\hline & & & Surgery & 68 & 14 & & \\
\hline \multirow[t]{2}{*}{ Ando and colleagues [47] } & SCC & 100 & CV & 100 & & 45 & NS \\
\hline & & & Surgery & 105 & & 48 & \\
\hline \multirow[t]{2}{*}{ Ando and colleagues [25] } & SCC & 100 & $\mathrm{CF}$ & 120 & & 61 & NS \\
\hline & & & Surgery & 122 & & 52 & \\
\hline
\end{tabular}

CF cisplatin + fluorouracil, CV cisplatin + vindesine, MS median survival, NS not significant, OS overall survival, SCC squamous cell carcinoma. 


\section{Adjuvant chemotherapy}

Adjuvant CT with cisplatin-based regimens compared with surgery alone has been examined in three separate phase III trials $[25,46,47]$ (Table 5). None of these trials reported a statistically significant difference in OS, although Ando and colleagues reported a 5-year OS advantage $(52 \%$ vs. $38 \%, P=0.041)$ in the $\mathrm{pN} 1$ subgroup patients [25].

Two JCOG trials studied adjuvant CT for resected SCC of the esophagus. In the first study, 205 patients with resected SCC of the esophagus were randomized to receive two cycles of adjuvant CT with cisplatin $70 \mathrm{mg} / \mathrm{m}^{2}$ (day 1) and vindesine $3 \mathrm{mg} / \mathrm{m}^{2}$ (day 1 ) or observation only. No significant benefit in survival was detected from the addition of this adjuvant CT regimen (5-year OS: $48.1 \%$ vs. $44.9 \%$ with observation; $P=0.55$ ) [47]. The follow-up JCOG 9402 study randomized 242 patients with resected SCC of the esophagus to two cycles of cisplatin $80 \mathrm{mg} / \mathrm{m}^{2}$ (day 1 ) and 5 -FU $800 \mathrm{mg} / \mathrm{m}^{2} /$ day (days 1 to 5 ) or observation. The addition of this adjuvant CT regimen improved the disease-free survival rate (from 45 to $55 \%$; $P=0.037)$ and the pN1 subgroup 5 -year OS (52\% vs. $38 \%$, $P=0.041)$; however, there was no significant difference in the 5 -year OS $(61 \%$ with CT vs. $52 \%$ with observation; $P=0.13)$ [25].

\section{Adjuvant chemoradiotherapy}

The efficacy of adjuvant CRT has not been compared with surgery alone in a randomized trial in patients with esophageal SSC. The National Comprehensive Cancer Network does recommend postoperative adjuvant CRT for stages II and III esophageal AC. This recommendation is based on a randomized phase III trial by Macdonald and colleagues that found adjuvant CRT improved 3 -year OS from 41 to $50 \%$ in $\mathrm{AC}$ of the stomach and gastroesophageal junction [48]. A small randomized trial of 45 patients compared adjuvant CT using cisplatin 50 $\mathrm{mg} / \mathrm{m}^{2}$ (days 1 and 15) and 5 -FU $300 \mathrm{mg} / \mathrm{m}^{2} /$ day (for 5 weeks) with adjuvant CRT after R0 resection of esophageal SCC. No significant difference in 5-year OS was demonstrated ( $38 \%$ CT vs. $50 \%$ CRT; $P=0.97$ ), but the study was limited by the small sample size [49].

\section{Discussion}

None of the randomized trials that compared neoadjuvant $\mathrm{RT}$ or $\mathrm{CT}$ with surgery alone in esophageal SCC has demonstrated an increase in OS in those patients treated with neoadjuvant RT or CT. Neoadjuvant CRT has been accepted recently for esophageal cancer because such a regimen increases the rates of $\mathrm{R} 0$ resection and local tumor control. The updated meta-analysis also favors the neoadjuvant CRT approach for patients with SCC [26]. Another recent meta-analysis demonstrated that the esophageal SCC in Europe and in the USA benefited from neoadjuvant CRT; however, patients in Asia did not benefit [50]. Ethnic difference makes it necessary to re-evaluate the role of neoadjuvant CRT in patients with SCC in Asia.

Phase III trials have compared adjuvant RT with surgery alone without demonstrating any OS benefit, except in stage III patients $(35.1 \%$ vs. $13.1 \%, P=0.003)$ [44]. The phase II nonrandomized trial for patients with node-positive (T3 or T4) tumors indicated that the outcomes of adjuvant CRT are better than the historical outcomes with surgery alone [49]. The retrospective study indicated that adjuvant RT was associated with a statistically significant improvement in survival, but only in those patients with three or more involved lymph nodes [45]. The addition of adjuvant CT only improved the pN1 subgroup 5-year OS [25]. The majority of the available evidence therefore currently reveals that only selected locally advanced esophageal SCC are more likely to benefit from the adjuvant therapy. The National Comprehensive Cancer Network recommends upfront surgery only for select patients with clinical T1 disease. For all other disease stages, CRT, preoperative CRT, or preoperative CT is recommended [51]. The current evidence reveals that primary surgery followed by adjuvant therapy should be used cautiously in clinical practice until appropriately powered randomized trials confirm the adjuvant treatment results of this disease.

Although both neoadjuvant CRT and adjuvant CRT have emerged as more useful options for the treatment of resectable esophageal SCC, it is hard to identify which is better based on current knowledge in the lack of head-to-head randomized controlled trials. Designing proper multidisciplinary studies that include use of novel systemic chemotherapies, optimizing radiation techniques, and identifying patient and tumor-specific markers predictive for response and/or toxicity remains an urgent need for the future. The approach is currently being explored in China by investigators of the ZTOG1201 trial, a multicenter phase II trial of neoadjuvant and adjuvant CRT in locally advanced esophageal cancer (NCT01463501).

Future trials should investigate further ways to improve upon current loco-regional control and survival. Opportunities for development include use of novel chemotherapies. Docetaxel was recently reported as a powerful anticancer agent for esophageal cancer in numerous trials. Cisplatin plus docetaxel, with or without 5-FU, has demonstrated activity in patients with locally advanced EGI or metastatic esophageal SCC [52-54]. A small-sample retrospective study has also showed that preoperative combined $\mathrm{CT}$ with docetaxel plus cisplatin and 5-FU followed by surgery provided a high response rate and a favorable survival benefit in patients with resectable esophageal SCC [55]. In the docetaxel plus 
cisplatin and 5-FU group, the overall response rate was 92.3\%; 30.8\% patients had complete response, $61.5 \%$ partial response, $7.7 \%$ stable disease, and 0 progressive disease. To validate the clinical significance of this novel CT regimen, large-sample randomized trials are essential.

\section{Conclusion}

None of the randomized trials that compared neoadjuvant RT or CT with surgery alone in esophageal SCC has demonstrated an increase in OS in those patients treated with neoadjuvant RT or CT. Neoadjuvant CRT has been accepted recently for esophageal cancer because such a regimen offers great opportunity for margin negative resection, improved loco-regional control and increased survival, and should be an optional treatment paradigm. The majority of the available evidence currently reveals that only selected locally advanced esophageal SCC are more likely to benefit from the adjuvant therapy. The focus of future trials should be on identification of the optimum regimen and should aim to minimize treatment toxicities and effect on quality of life, as well as attempt to identify and select those patients most likely to benefit from specific treatment options.

\section{Abbreviations}

AC: adenocarcinoma; $\mathrm{Cl}$ : confidence interval; $\mathrm{CT}$ : chemotherapy; CRT: chemoradiotherapy; 5-FU: fluorouracil; HR: hazard ratio; JCOG: Japan Clinical Oncology Group; OS: overall survival; RT: radiotherapy; SCC: squamous cell carcinoma.

\section{Competing interests}

The authors declare that they have no competing interests.

\section{Authors' contributions}

All authors contributed equally to this work and approved the final manuscript.

\section{Acknowledgments}

Special thanks to Feng-Ming (Spring) Kong for contribution.

\section{Author details}

'Department of Radiation Oncology, Zhejiang Cancer Hospital, Hangzhou 310022, Zhejiang, People's Republic of China. ${ }^{2}$ Department of Medical Oncology, Zhejiang Cancer Hospital, Hangzhou 310022, Zhejiang, People's Republic of China. ${ }^{3}$ Department of Thoracic Surgery, Zhejiang Cancer Hospital, Hangzhou 310022, Zhejiang, People's Republic of China.

Received: 1 April 2012 Accepted: 27 July 2012

Published: 25 August 2012

\section{References}

1. Bollschweiler E, Wolfgarten E, Gutschow C, Hölscher AH: Demographic variations in the rising incidence of esophageal adenocarcinoma in white males. Cancer 2001, 92:549-555.

2. Pohl H, Welch HG: The role of overdiagnosis and reclassification in the marked increase of esophageal adenocarcinoma incidence. J Natl Cancer Inst 2005, 97:142-146.

3. Kamangar F, Dores GM, Anderson WF: Patterns of cancer incidence, mortality, and prevalence across five continents: defining priorities to reduce cancer disparities in different geographic regions of the world. J Clin Oncol 2006, 24:2137-2150.
4. Siegel R, Naishadham D, Jemal A: Cancer statistics 2012. CA Cancer J Clin 2012, 62:10-29.

5. Mariette C, Finzi L, Piessen G, Van Seuningen I, Triboulet JP: Esophageal carcinoma: prognostic differences between squamous cell carcinoma and adenocarcinoma. World J Surg 2005, 29:39-45.

6. Hölscher AH, Bollschweiler E, Schneider PM, Siewert JR: Prognosis of early esophageal cancer. Comparison between adeno- and squamous cell carcinoma. Cancer 1995, 76:178-186.

7. Bollschweiler E, Metzger R, Drebber U, Baldus S, Vallböhmer D, Kocher M, Hölscher AH: Histological type of esophageal cancer might affect response to neo-adjuvant radiochemotherapy and subsequent prognosis. Ann Oncol 2009, 20:231-238.

8. Stein HJ, Feith M, Bruecher BL, Naehrig J, Sarbia M, Siewert JR: Early esophageal cancer: pattern of lymphatic spread and prognostic factors for long-term survival after surgical resection. Ann Surg 2005, 242:566-573. discussion 573-575.

9. Bollschweiler E, Schröder W, Hölscher AH, Siewert JR: Preoperative risk analysis in patients with adenocarcinoma or squamous cell carcinoma of the oesophagus. Br J Surg 2000, 87:1106-1110.

10. Siewert JR, Ott K: Are squamous and adenocarcinomas of the esophagus the same disease? Semin Radiat Oncol 2007, 17:38-44.

11. Launois B, Delarue D, Campion JP, Kerbaol M: Preoperative radiotherapy for carcinoma of the esophagus. Surg Gynecol Obstet 1981, 153:690-692.

12. Gignoux M, Roussel A, Paillot B, Gillet M, Schlag P, Favre JP, Dalesio O, Buyse $\mathrm{M}$, Duez N: The value of preoperative radiotherapy in esophageal cancer: results of a study by the EORTC. World I Surg 1987, 11:426-432.

13. Arnott SJ, Duncan W, Kerr GR, Walbaum PR, Cameron E, Jack WJ, Mackillop WJ: Low dose preoperative radiotherapy for carcinoma of the oesophagus: results of a randomized clinical trial. Radiother Oncol 1992, 24:108-113.

14. Nygaard K, Hagen S, Hansen HS, Hatlevoll R, Hultborn R, Jakobsen A Mäntyla M, Modig H, Munck-Wikland E, Rosengren B: Pre-operative radiotherapy prolongs survival in operable esophageal carcinoma: a randomized, multicenter study of pre-operative radiotherapy and chemotherapy. The second Scandinavian trial in esophageal cancer. World J Surg 1992, 16:1104-1109. discussion 1110.

15. Wang M, Gu XZ, Yin WB, Huang GJ, Wang LJ, Zhang DW: Randomized clinical trial on the combination of preoperative irradiation and surgery in the treatment of esophageal carcinoma: report on 206 patients. Int $J$ Radiat Oncol Biol Phys 1989, 16:325-327.

16. Arnott SJ, Duncan W, Gignoux M, Girling DJ, Hansen HS, Launois B, Nygaard K, Parmar MK, Rousell A, Spiliopoulos G, Stewart LA, Tierney JF, Wang M, Rhugang Z: Preoperative radiotherapy for esophageal carcinoma. Cochrane Database Syst Rev 2005, 4:CD001799.

17. Schwer AL, Ballonoff A, McCammon R, Rusthoven K, D'Agostino RB Jr, Schefter TE: Survival effect of neoadjuvant radiotherapy before esophagectomy for patients with esophageal cancer: a surveillance, epidemiology, and end-results study. Int I Radiat Oncol Biol Phys 2009, 73:449-455

18. Schlag PM: Randomized trial of preoperative chemotherapy for squamous cell cancer of the esophagus. The Chirurgische Arbeitsgemeinschaft Fuer Onkologie der Deutschen Gesellschaft Fuer Chirurgie Study Group. Arch Surg 1992, 127:1446-1450.

19. Maipang T, Vasinanukorn P, Petpichetchian C, Chamroonkul S, Geater A, Chansawwaang S, Kuapanich R, Panjapiyakul C, Watanaarepornchai S, Punperk S: Induction chemotherapy in the treatment of patients with carcinoma of the esophagus. J Surg Oncol 1994, 56:191-197.

20. Law S, Fok M, Chow S, Chu KM, Wong J: Preoperative chemotherapy versus surgical therapy alone for squamous cell carcinoma of the esophagus: a prospective randomized trial. J Thorac Cardiovasc Surg 1997, 114:210-217.

21. Ancona E, Ruol A, Santi S, Merigliano S, Sileni VC, Koussis H, Zaninotto G, Bonavina L, Peracchia A: Only pathologic complete response to neoadjuvant chemotherapy improves significantly the long term survival of patients with resectable esophageal squamous cell carcinoma: final report of a randomized, controlled trial of preoperative chemotherapy versus surgery alone. Cancer 2001, 91:2165-2174.

22. Kelsen DP, Winter KA, Gunderson LL, Mortimer J, Estes NC, Haller DG, Ajani JA, Kocha W, Minsky BD, Roth JA, Willett CG: Long-term results of RTOG trial 8911 (USA Intergroup 113): a random assignment trial comparison 
of chemotherapy followed by surgery compared with surgery alone for esophageal cancer. I Clin Oncol 2007, 25:3719-3725.

23. Allum WH, Stenning SP, Bancewicz J, Clark PI, Langley RE: Long-term results of a randomized trial of surgery with or without preoperative chemotherapy in esophageal cancer. J Clin Oncol 2009, 27:5062-5067.

24. Sato $M$, Ando N: Neoadjuvant chemotherapy followed by surgery as standard treatment for stage II + III thoracic esophageal squamous cell carcinoma in Japan. Nihon Geka Gakkai Zasshi 2011, 112:104-110.

25. Ando N, lizuka T, Ide H, Ishida K, Shinoda M, Nishimaki T, Takiyama W, Watanabe H, Isono K, Aoyama N, Makuuchi H, Tanaka O, Yamana H, Ikeuchi S, Kabuto T, Nagai K, Shimada Y, Kinjo Y, Fukuda H: Surgery plus chemotherapy compared with surgery alone for localized squamous cell carcinoma of the thoracic esophagus: a Japan Clinical Oncology Group Study - JCOG9204. J Clin Oncol 2003, 21:4592-4596.

26. Sjoquist KM, Burmeister BH, Smithers BM, Zalcberg JR, Simes RJ, Barbour A, Gebski V: Survival after neoadjuvant chemotherapy or chemoradiotherapy for resectable oesophageal carcinoma: an updated meta-analysis. Lancet Oncol 2011, 12:681-692.

27. Herskovic A, Martz K, al-Sarraf M, Leichman L, Brindle J, Vaitkevicius V, Cooper J, Byhardt R, Davis L, Emami B: Combined chemotherapy and radiotherapy compared with radiotherapy alone in patients with cancer of the esophagus. N Engl J Med 1992, 326:1593-1598.

28. Overgaard J: Hypoxic radiosensitization: adored and ignored. J Clin Oncol 2007, 25:4066-4074.

29. Albertsson M: Chemoradiotherapy of esophageal cancer. Acta Oncol 2002, 41:118-123.

30. Bosset JF, Gignoux M, Triboulet JP, Tiret E, Mantion G, Elias D, Lozach P, Ollier JC, Pavy JJ, Mercier M, Sahmoud T: Chemoradiotherapy followed by surgery compared with surgery alone in squamous-cell cancer of the esophagus. N Engl J Med 1997, 337:161-167.

31. Mariette C, Seitz JF, Maillard E: Impact of neoadjuvant chemoradiation in localized esophageal cancer: results of a randomized, controlled phase III trial. FFCD 9901 [abstract 8000]. In Proceedings of the 35th ESMO Congress. Milan; 2010

32. Lee JL, Park SI, Kim SB, Jung HY, Lee GH, Kim JH, Song HY, Cho K, Kim WK, Lee JS, Kim SH, Min YI: A single institutional phase III trial of preoperative chemotherapy with hyperfractionation radiotherapy plus surgery versus surgery alone for resectable esophageal squamous cell carcinoma. Ann Oncol 2004, 15:947-954.

33. Natsugoe $S$, Okumura H, Matsumoto M, Uchikado Y, Setoyama T, Yokomakura N, Ishigami S, Owaki T, Aikou T: Randomized controlled study on preoperative chemoradiotherapy followed by surgery versus surgery alone for esophageal squamous cell cancer in a single institution. Dis Esophagus 2006, 19:468-472.

34. Burmeister BH, Smithers BM, Gebski V, Fitzgerald L, Simes RJ, Devitt P, Ackland S, Gotley DC, Joseph D, Millar J, North J, Walpole ET, Denham JW: Surgery alone versus chemoradiotherapy followed by surgery for resectable cancer of the oesophagus: a randomised controlled phase III trial. Lancet Oncol 2005, 6:659-668.

35. Tepper J, Krasna MJ, Niedzwiecki D, Hollis D, Reed CE, Goldberg R, Kiel K, Willett C, Sugarbaker D, Mayer R: Phase III trial of trimodality therapy with cisplatin, fluorouracil, radiotherapy, and surgery compared with surgery alone for esophageal cancer: CALGB 9781. J Clin Oncol 2008, 26:1086-1092

36. Gaast AV, van Hagen $P$, Hulshof $M$, Richel $D$, van Berge Henegouwen $M L$ Nieuwenhuijzen GA, Plukker JT, Bonenkamp JJ, Steyerberg EW, Tilanus HW: Esophagogastric junction cancer: results from a multicenter randomized phase III study [abstract]. J Clin Oncol 2010, 28:4004.

37. Kranzfelder M, Schuster T, Geinitz H, Friess H, Büchler P: Meta-analysis of neoadjuvant treatment modalities and definitive non-surgical therapy for oesophageal squamous cell cancer. Br J Surg 2011, 98:768-783.

38. Akutsu Y, Matsubara H, Shuto K, Uesato M, Mori M, Hoshino I, Shiratori T, Miyazawa $Y$, Ito $H$, Uno T: Clinical and pathologic evaluation of the effectiveness of neoadjuvant chemoradiation therapy in advanced esophageal cancer patients. World J Surg 2009, 33:1002-1009.

39. Kunath U, Fischer P: Radical nature and life expectancy in the surgical treatment of esophageal and cardial carcinoma. Dtsch Med Wochenschr 1984, 109:450-453.

40. Ténière P, Hay JM, Fingerhut A, Fagniez PL: Postoperative radiation therapy does not increase survival after curative resection for squamous cell carcinoma of the middle and lower esophagus as shown by a multicenter controlled trial. French University Association for Surgical Research. Surg Gynecol Obstet 1991, 173:123-130.

41. Fok M, Sham JS, Choy D, Cheng SW, Wong J: Postoperative radiotherapy for carcinoma of the esophagus: a prospective, randomized controlled study. Surgery 1993, 113:138-147.

42. Zieren HU, Müller JM, Jacobi CA, Pichlmaier H, Müller RP, Staar S: Adjuvant postoperative radiation therapy after curative resection of squamous cell carcinoma of the thoracic esophagus: a prospective randomized study. World J Surg 1995, 19:444-449.

43. Xiao ZF, Yang ZY, Liang J, Miao YJ, Wang M, Yin WB, Gu XZ, Zhang DC, Zhang RG, Wang LJ: Value of radiotherapy after radical surgery for esophageal carcinoma: a report of 495 patients. Ann Thorac Surg 2003, 75:331-336.

44. Malthaner RA, Wong RK, Rumble RB, Zuraw L: Neoadjuvant or adjuvant therapy for resectable esophageal cancer: a systematic review and meta-analysis. BMC Med 2004, 2:35-52.

45. Chen J, Zhu J, Pan J, Zhu KS, Zheng XW, Chen MQ, Wang JZ, Liao ZX: Postoperative radiotherapy improved survival of poor prognostic squamous cell carcinoma esophagus. Ann Thorac Surg 2010, 90:435-442.

46. Pouliquen $\mathrm{X}$, Levard H, Hay JM, McGee K, Fingerhut A, Langlois-Zantin O: 5-Fluorouracil and cisplatin therapy after palliative surgical resection of squamous cell carcinoma of the esophagus. A multicenter randomized trial. French Associations for Surgical Research. Ann Surg 1996, 223:127-133.

47. Ando N, lizuka T, Kakegawa T, Lsono K, Watanabe H, Lde H, Tanaka O, Shinoda M, Takiyama W, Arimori M, Lshida K, Tsugane S: A randomized trial of surgery with and without chemotherapy for localized squamous carcinoma of the thoracic esophagus: the Japan Clinical Oncology Group Study. J Thorac Cardiovasc Surg 1997, 114:205-209.

48. Macdonald JS, Smalley SR, Benedetti J, Hundahl SA, Estes NC, Stemmermann GN, Haller DG, Ajani JA, Gunderson LL, Jessup JM, Martenson JA: Chemoradiotherapy after surgery compared with surgery alone for adenocarcinoma of the stomach or gastroesophageal junction. N Engl J Med 2001, 345:725-730.

49. Tachibana M, Yoshimura H, Kinugasa S, Shibakita M, Dhar DK, Ueda S, Fuji T, Nagasue N: Postoperative chemotherapy vs chemoradiotherapy for thoracic esophageal cancer: a prospective randomized clinical trial. Eur J Surg Oncol 2003, 29:580-587.

50. Jin HL, Zhu H, Ling TS, Zhang HJ, Shi RH: Neoadjuvant chemoradiotherapy for resectable esophageal carcinoma: a meta-analysis. World I Gastroenterol 2009, 15:5983-5991.

51. National Comprehensive Cancer Network practice guidelines in Oncology. Version 2 http://www.nccn.org/professionals/physician_gls/f_guidelines.asp.

52. Ajani JA, Fodor MB, Tjulandin SA, Moiseyenko VM, Chao Y, Cabral Filho S, Majis A, Assadourian S, Van Cutsem E: Phase II multi-institutional randomized trial of docetaxel plus cisplatin with or without fluorouracil in patients with untreated, advanced gastric, or gastroesophageal adenocarcinoma. J Clin Oncol 2005, 23:5660-5667.

53. Van Cutsem E, Moiseyenko VM, Tjulandin S, Majlis A, Constenla M, Boni C, Rodrigues A, Fodor M, Chao Y, Voznyi E, Risse ML, Ajani JA: Phase III study of docetaxel and cisplatin plus fluorouracil compared with cisplatin and fluorouracil as first-line therapy for advanced gastric cancer: a report of the V325 Study Group. J Clin Oncol 2006, 24:4991-4997.

54. Kim JY, Do YR, Park KU, Kim MK, Lee KH, Bae SH, Ryoo HM, Baek JH, Song HS: A multi-center phase II study of docetaxel plus cisplatin as first-line therapy in patients with metastatic squamous cell esophageal cancer. Cancer Chemother Pharmacol 2010, 66:31-36.

55. Yoshida T, Seike J, Miyoshi T, Yamai H, Takechi H, Yuasa Y, Furukita Y, Yamamoto Y, Umemoto A, Tangoku A: Preoperative chemotherapy with weekly docetaxel plus low-dose cisplatin and 5-fluorouracil for stage II/III squamous cell carcinoma of the esophagus. Esophagus 2010, 7:95-100.

doi:10.1186/1477-7819-10-173

Cite this article as: Xu et al: Neoadjuvant versus adjuvant treatment: which one is better for resectable esophageal squamous cell carcinoma? World Journal of Surgical Oncology 2012 10:173. 